\title{
Effect of terpene treatment on tomato fruit
}

\author{
Bruna Orsi ${ }^{1}$ (D) Christian Aparecido Demétrio² (D), Jessica Fernanda Oliveira Jacob² (D), Paulo Hercílio \\ Viegas Rodrigues2,* (iD \\ 1. Universidade de São Paulo rợ - Escola de Agricultura “Luiz de Queiroz" - Laboratório de Fisiologia e Bioquímica Pós-Colheita - Piracicaba (SP), Brazil. \\ 2. Universidade de São Paulo rọ - Escola de Agricultura "Luiz de Queiroz" - Laboratório de Cultura de Tecidos de Plantas Ornamentais - \\ Piracicaba (SP), Brazil. \\ Received: May 6, 2021 | Accepted: Nov. 3, 2021 \\ Section Editor: Gabriel Constantino Blain \\ *Corresponding author: phrviegas@usp.br \\ How to cite: Orsi, B., Demétrio, C. A., Jacob, J. F. O., Rodrigues, P. H. V. (2022). Effect of terpene treatment on tomato fruit. Bragantia, 81, e0322. \\ https://doi.org/10.1590/1678-4499.20210134
}

\begin{abstract}
Terpenes are secondary metabolites produced from isopentenyl pyrophosphate (IPP) and dimethylallyl pyrophosphate (DMAPP). Considering their role against biotic and abiotic stress conditions, the D-limonene, a terpene recognized for its roles in plant defense and as pigment molecules, was tested to monitor its impact in the accumulation of carotenoid terpene pigments during tomato fruit ripening. The concentrations of $0.0,1.0$, and $2.0 \mathrm{~mL} \cdot \mathrm{L}^{-1}$ were sprayed weekly on tomato plants 'Micro-Tom' until the harvest. The fruits were harvested at the mature green stage (MG), the breaker stages (BR), three days after the breaker (BR +3 ), the red ripe stage (RR), and the concentration of carotenoids was evaluated. The application of D-limonene enhanced the concentration of carotenoids in the early stages of tomato fruit ripening and ripe fruits, and the accumulation of carotenoids was greater following dose increment. This result can bring important contributions to horticulture and food nutrition by linking plant defense and the accumulation of molecules with recognized antioxidant capacity in fruit.
\end{abstract}

Key words: essential oil, terpenes, plant defense, pigments.

Terpenoids are one of the largest and most diverse classes of plant metabolites. All terpenoids are formed from repetitive 5-carbon isoprene units, isopentenyl pyrophosphate (IPP), and its isomer, dimethylallyl-pyrophosphate (DMAPP) (Singh and Sharma 2015). This class includes molecules of primary metabolism such as the phytohormones gibberellin and abscisic acid, pigments such as chlorophyll and carotenoids, and sterols that influence the membrane structure (Aharoni et al. 2005). In addition, terpenoids also include monoterpenes (C10), sesquiterpenes (C15), and diterpenes (C20), which are recognized as secondary metabolites that act in the defense of plants against biotic and abiotic stresses (Singh and Sharma 2015). Considering they are volatile in environmental condition; lower molecular weight terpenes can also act as signaling molecules in communication intra- and interplants when emitted (Lackus et al. 2018). Due to their recognized role in plant defense, terpenes are used as an active or inert ingredient in eco-friendly insecticides, such as D-limonene, one of the main constituents of products available on the market, due to its low toxicity to animals (Campolo et al. 2020; Menezes 2005).

Besides its application as insecticide sprays, mosquito larvicides, and insect repellents (Hollingsworth 2005), D-limonene has recognized antimicrobial activity against a wide variety of microorganisms such as Escherichia coli, Staphylococcus aureus, Bacillus subtilis, Saccharomyces cerevisiae (Zahi et al. 2017) and increases plant resistance against pathogens such as Botrytis cinerea (Vega-Vásquez et al. 2021), Penicillium italicum and Penicillium digitatum (Tao et al. 2014).

D-limonene $\left(\mathrm{C}_{10} \mathrm{H}_{16}\right)$ is a monocyclic monoterpene. Its synthesis occurs from a head-to-tail condensation between two isoprene units, IPP and DMAPP, that leads to the formation of its 10-carbon precursor, geranyl pyrophosphate (GPP), which is also an intermediate for the synthesis of carotenoids pigments (Kiyota et al. 2014).

Carotenoids (C40) are terpenoids derivatives formed from eight isoprene units. After the formation of GPP, two other enzymes lead to the formation of farnesyl diphosphate (FPP) and geranylgeranyl diphosphate (GGPP). The first colorless 
carotenoid, phytoene (C40), is formed from the condensation of two GGPP molecules (C20). Phytoene undergoes dehydrogenation by two enzymes, PDS and ZDS, that lead to the formation of lycopene (Liu et al. 2003).

Carotenoids are important pigments known mainly for their role in photosynthesis, acting as protectors of the photosynthetic apparatus and as accessory pigments for light-harvesting, absorbing light along with the chlorophylls (Cazzaniga et al. 2016). Due to their role as pigments, carotenoid accumulation is mainly related to the attraction of seed dispersers in fruits, providing the distinct color of each species (Yuan et al. 2015). Furthermore, since they are precursors of volatile compounds, the presence of carotenoids gives the aroma and flavor characteristics of the fruits (Tieman et al. 2012).

Tomato fruit (Lycopersicon esculentum Mill. [Solanum lycopersicum L.]) represents one of the most well-known sources of carotenoids and is characterized by the high content of lycopene, that grants the fruit its red color (Story et al. 2010). The expressive synthesis of lycopene and the degradation of chlorophyll result in a dramatic shift in the color of the epidermis during tomato fruit ripening. Such characteristic makes the tomato fruit one of the favorite model systems for studying carotenoids (Liu et al. 2003). Considering lycopene free radicals scavenging capacity, the insertion of tomatoes into the diet has been recommended by the American Heart Association (Van Horn et al. 2016) and is associated with a reduction in cardiovascular diseases (Cheng et al. 2019).

Previous reports show the interaction between D-limonene and carotenoids in fruits. Down-regulation of carotenoid biosynthetic genes was observed in a transgenic orange line lacking D-limonene synthase activity after the fruits were inoculated with the fungus Phyllosticta citricarpa (Rodríguez et al. 2018). However, the down-regulated expression of D-limonene synthase did not lead to changes in carotenoids levels in orange fruit that were not inoculated whit a pathogen (Rodríguez et al. 2014), which shows the complex interaction between related isoprenoids biosynthetic pathways and its relationship with the plant-pathogen interaction.

Furthermore, the overexpression of the SIMX1 gene in tomato plants leads to an enhanced number of trichomes in the surface of the leaves, which produced higher quantities of terpenoids and showed up-regulated expression of terpenoid biosynthetic genes, including D-limonene synthase (Ewas et al. 2017). Surprisingly, the overexpression SlMX1 plants also exhibited darker fruits due to the enhanced content of carotenoids (Ewas et al. 2016), which suggests that factors regulating defense mechanisms in green tissues also regulate the synthesis of carotenoid pigments in fruits.

Considering the complex interaction between terpenoids reported in previous works and the lack of information about the effect of exogenous supplementation of monoterpenes in the levels of other related isoprenoids, this study aimed to verify, if after spraying tomato plants with a solution of natural $\mathrm{D}$-limonene, there is a secondary effect in the content of total carotenoids during fruit ripening.

Seeds of L. esculentum Mill. (Solanum lycopersicum L.) 'Micro-Tom' were sown in plastic trays ( 120 cells) with commercial substrate Plantmax HT (pine bark 60\%, peat 20\%, expanded vermiculite 20\%). After two weeks, the seedlings were transferred in final pots $(14.5 \mathrm{~cm}$ diameter $\times 10.5 \mathrm{~cm}$ height) with the same substrate in a greenhouse located at Piracicaba, São Paulo, Brazil. In this region, the climate is Cwa, according to Köppen classification (i.e., subtropical climate with dry months in winter-July to August-and rains in summer). During the period of crop cultivation, the average temperature inside the greenhouse was $24^{\circ} \mathrm{C}$. Nutritional supplementation was performed at the time of sowing and the anthesis, incorporating to the substrate $1.0 \mathrm{~g} \cdot \mathrm{L}^{-1}$ of NPK 10:10:10 and $4 \mathrm{~g} \cdot \mathrm{L}^{-1}$ of dolomite limestone $\left(\mathrm{MgCO}_{3}+\mathrm{CaCO}_{3}\right)$. Foliar fertilization was performed weekly from anthesis ( $\sim 35$ days after sowing), with $1 \mathrm{~g} \cdot \mathrm{L}^{-1}$ of Peters 20-20-20 fertilizer (NPK).

The treatments consisted in different concentrations of D-limonene: (1) 0.0, (2) 1.0, and (3) $2.0 \mathrm{~mL} \cdot \mathrm{L}^{-1}$. The treatments solutions were prepared using natural citrus peel essential oil (Pro Lyks Hydroplan-EB, 58\% Citrus sinensis peel oil coldpressing technique) - natural ingredient IBD certificated (input approved for agriculture use in accordance with NOP/US standards, IBD/IFOAM, COR/Canada, EEC 889/08 and Brazilian law 10,831/2003), diluted in deionized water (alone served as the control).

The applications were made weekly by spraying the entire length of the plant with Stihl SG 11 hand pump sprayer with conical tip $\left(\mathrm{v}=1.5 \mathrm{~L}\right.$; pression $\left.=3.0 \mathrm{bar} ; \mathrm{Q}=0.6 \mathrm{~L} \cdot \mathrm{min}^{-1}\right)$, until the harvest (70 days after sowing). No pesticides were sprayed on plants used in the trials.

The fruits were harvested at the mature green stage (MG) and the concentration of carotenoids was evaluated. The MG stage was considered the one in which the fruits stopped growing and presented the typical jelly-like consistency in the locular content (Sorensen 1955). The fruits were also analyzed during ripening in the breaker stages (BR), characterized 
by the beginning of the change in the color of the fruits; three days after the breaker $(B R+3)$ and at the red ripe stage (RR), at the end of ripening. Fruits were monitored at different stages of development due to the dramatic shift in tomato color promoted by the expressive synthesis of carotenoids during the advancement in ripening. The statistical design was completely randomized, with 4 repetitions of 10 fruits each.

The quantification of total carotenoids was carried out with approximately $50 \mathrm{mg}$ of lyophilized sample. The samples were extracted with $10 \mathrm{~mL}$ of acetone/hexane solution (1:1) and kept at room temperature for $2 \mathrm{~h}$, in the dark. The samples were centrifuged for $7 \mathrm{~min}$ at 13,000 $\mathrm{g}$ and the supernatant was collected. The readings were performed on a spectrophotometer (Bel V-M5, Italy) at a wavelength of $450 \mathrm{~nm}$. The data were represented in $\mu \mathrm{g} \cdot \mathrm{g}^{-1} \mathrm{dry}$ weight.

Statistical analyzes were performed using the R Studio software (version 3.5.2). The results were subjected to analysis of variance and expressed as mean \pm standard deviation. The normality and homogeneity of the data were verified by the Shapiro-Wilk and Bartlett tests, respectively. Statistical significance was accessed by the Tukey's test ( $\mathrm{p} \leq 0.05)$.

The supply of an exogenous source of D-limonene altered the concentration of carotenoids at all stages of fruit ripening (Fig. 1). Differences were observed right at the MG stage, where the application of D-limonene significantly increased the concentration of carotenoids in the fruits, being greater with the increase of the dose provided.

The main carotenoids found in green tomato fruits are $\beta$-carotene and xanthophylls, present in chloroplasts and recognized for their role in capturing light and protecting the photosynthetic apparatus (Almeida et al. 2015). With the advancement of ripening, the synthesis of carotenoids increases significantly and favors the accumulation of lycopene, which is stored in lipophilic structures in the chromoplast (Ronen et al. 2000). Therefore, the greater accumulation of carotenoids in green fruits, promoted by the application of D-limonene is interesting, since, at this stage, the concentration of total carotenoids is naturally lower when compared to mature fruits containing chromoplast.

The BR stage of tomato ripening is characterized by the degradation of chloroplast structures, which are converted to chromoplasts (Egea et al. 2011). At this stage, the most expressive synthesis of carotenoids is initiated. Interestingly, the control fruits showed a higher concentration of carotenoids in the breaker stage, which, after 3 days, was similar to the values found in the plants that received the treatment, regardless of the treatment dose (Fig. 1). Despite this, at the end of fruit ripening, when the accumulation of carotenoids is more intense, the application of D-limonene significantly increased the concentration of these pigments and, as observed in green fruits, the concentration of carotenoids was higher following dose increment.

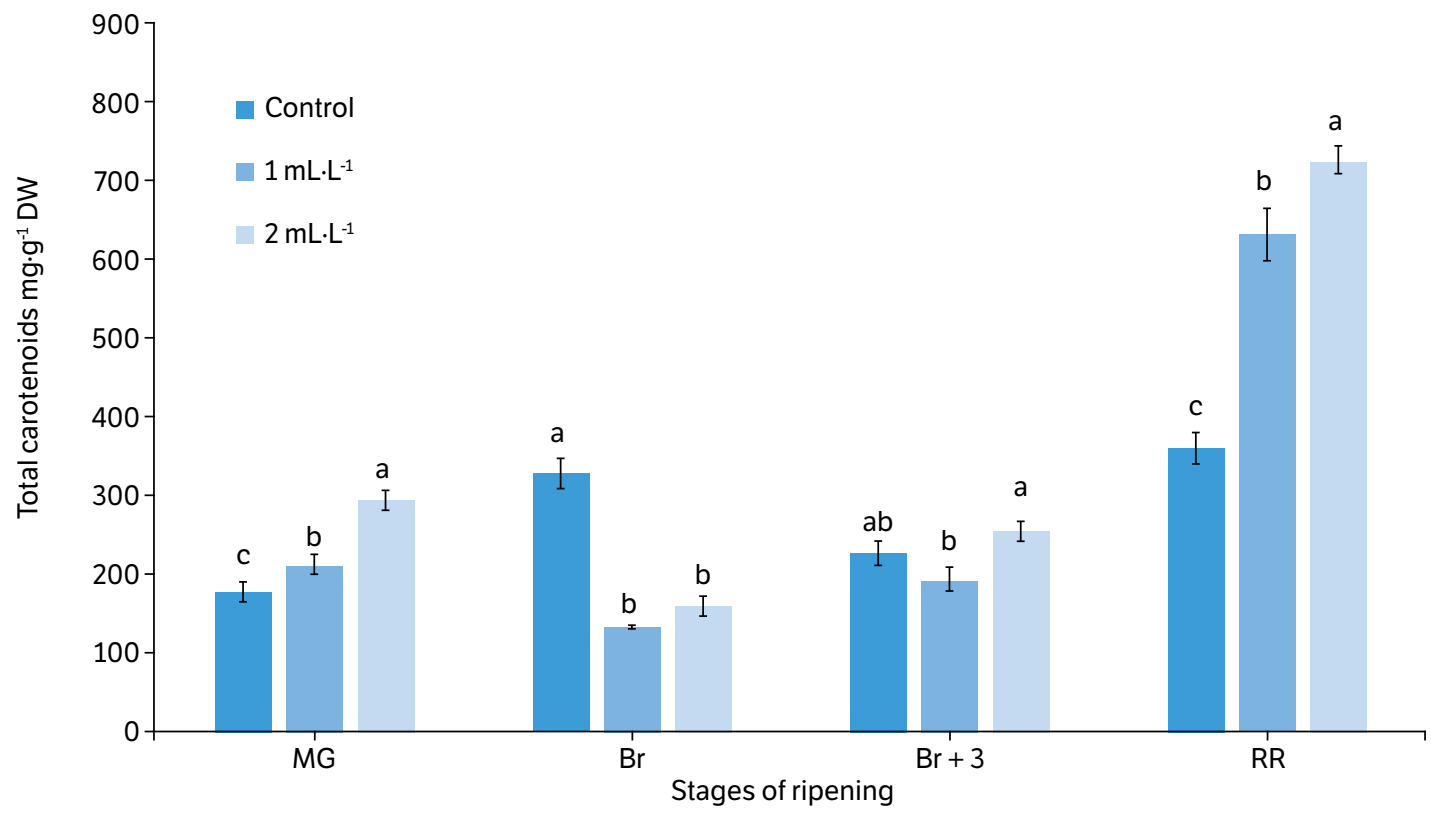

Source: Elaborated by the authors.

Figure 1. The concentration of total carotenoids in tomato fruits submitted to the application of different concentrations of $D$-limonene, in mature green stage (MG), breaker (BR), three days after the breaker (BR +3 ), and red ripe (RR). Vertical bars indicate the standard deviation of the mean. Means followed by the same letters do not differ among each other. Distinct lowercase letters denote different means by Tukey's test $(\alpha \leq 0.05)$ for comparison of different D-limonene concentrations. 
The enhancement in the content of total carotenoids is an interesting trait for the food industry since carotenoids have a recognized role in the definition of aroma, flavor, and nutritional quality of tomato fruit (Vogel et al. 2010). Furthermore, the presence of pigments is related to greater acceptance by consumers, who associate the intense color of the fruits with higher quality (Domínguez et al. 2020; Vogel et al. 2010). In summary, this result suggests that the supply of an exogenous source of D-limonene to tomato plants can increase the concentration of total carotenoids in fruits. Further studies may address if this effect was promoted by a metabolic diversion, since carotenoids are related isoprenoids and share common precursors with D-limonene.

Overall, this study demonstrates that exogenous application of the terpene D-limonene increases the concentration of carotenoids in ripe tomato fruit, and the effect on the concentration of carotenoids is observed even at the initial stage of fruit ripening before the expressive accumulation of pigments.

\section{AUTHORS' CONTRIBUTION}

Conceptualization: Orsi B. and Rodrigues P. H. V..; Methodology: Orsi B.: Rodrigues P. H. V. and Demetrio C. A.; Investigation: Orsi B.: Rodrigues P. H. V.: Demetrio C. A. and Jacob J. F. O.; Writing - Original Draft: Orsi B. and Rodrigues P. H. V.; Writing - Review and Editing: Orsi B. and Rodrigues P. H. V.; Supervision: Orsi B. and Jacob J. F. O.

\section{DATA AVAILABILITY STATEMENT}

All data sets were generated or analyzed in the current study.

\section{FUNDING}

Coordenação de Aperfeiçoamento de Pessoal de Nível Superior

[https://doi.org/10.13039/501100002322]

Finance Code 001

\section{ACKNOWLEDGEMENTS}

We are grateful to CAPES for granting a scholarship to the first author.

\section{REFERENCES}

Aharoni, A., Jongsma, M. A. and Bouwmeester, H. J. (2005). Volatile science? Metabolic engineering of terpenoids in plants. Trends in Plant Science, 10, 594-602. https://doi.org/10.1016/j.tplants.2005.10.005

Almeida, J., Asís, R., Molineri, V. N., Sestari, I., Lira, B. S., Carrari, F., Peres, L. E. P. and Rossi, M. (2015). Fruits from ripening impaired, chlorophyll degraded and jasmonate insensitive tomato mutants have altered tocopherol content and composition. Phytochemistry, 111, 72-83. https://doi.org/10.1016/j.phytochem.2014.11.007

Campolo, O., Puglisi, I., Barbagallo, R. N., Cherif, A., Ricupero, M., Biondi, A., Palmeri, V., Baglieri, A. and Zappalà, L. (2020). Side effects of two citrus essential oil formulations on a generalist insect predator, plant and soil enzymatic activities. Chemosphere, $257,127252$. https://doi.org/10.1016/j.chemosphere.2020.127252 
Cazzaniga, S., Bressan, M., Carbonera, D., Agostini, A., Dall'Osto, L. (2016). Differential roles of carotenes and xanthophylls in photosystem I photoprotection. Biochemistry 55, 3636-3649. https://doi.org/10.1021/acs.biochem.6b00425

Cheng, H. M., Koutsidis, G., Lodge, J. K., Ashor, A. W., Siervo, M. and Lara, J. (2019). Lycopene and tomato and risk of cardiovascular diseases: A systematic review and meta-analysis of epidemiological evidence. Critical Reviews in Food Science and Nutrition, 59, 141158. https://doi.org/10.1080/10408398.2017.1362630

Domínguez, R., Gullón, P., Pateiro, M., Munekata, P. E. S., Zhang, W. and Lorenzo, J. M. (2020). Tomato as potential source of natural additives for meat industry: A review. Antioxidants, 9, 73. https://doi.org/10.3390/antiox9010073

Egea, I., Bian, W., Barsan, C., Jauneau, A., Pech, J.-C., Latché, A., Li, Z. and Chervin, C. (2011). Chloroplast to chromoplast transition in tomato fruit: Spectral confocal microscopy analyses of carotenoids and chlorophylls in isolated plastids and time-lapse recording on intact live tissue. Annals of Botany. 108, 291-297. https://doi.org/10.1093/aob/mcr140

Ewas, M., Gao, Y., Ali, F., Nishawy, E. M., Shahzad, R., Subthain, H., Amar, M., Martin, C. and Luo, J. (2017). RNA-seq reveals mechanisms of SIMX1 for enhanced carotenoids and terpenoids accumulation along with stress resistance in tomato. Sci. Bull. 62, 476-485. https:// doi.org/10.1016/j.scib.2017.03.018

Ewas, M., Gao, Y., Wang, S., Liu, X., Zhang, H., Nishawy, E. M. E., Ali, F., Shahzad, R., Ziaf, K., Subthain, H., Martin, C. and Luo, J. (2016). Manipulation of SIMXI for enhanced carotenoids accumulation and drought resistance in tomato. Science Bulletin, 61, 1413-1418. https:// doi.org/10.1007/s11434-016-1108-9

Hollingsworth, R. G. (2005). Limonene, a citrus extract, for control of mealybugs and scale insects. Journal of Economic Entomology, 98, 772-779. https://doi.org/10.1603/0022-0493-98.3.772

Kiyota, H., Okuda, Y., Ito, M., Hirai, M. Y. and Ikeuchi, M. (2014). Engineering of cyanobacteria for the photosynthetic production of limonene from $\mathrm{CO}_{2}$. Journal Biotechnology, 185, 1-7. https://doi.org/10.1016/j.jbiotec.2014.05.025

Lackus, N. D., Lackner, S., Gershenzon, J., Unsicker, S. B. and Köllner, T. G. (2018). The occurrence and formation of monoterpenes in herbivore-damaged poplar roots. Scientific Reports, 8, 17936. https://doi.org/10.1038/s41598-018-36302-6

Liu, Y.-S., Gur, A., Ronen, G., Causse, M., Damidaux, R., Buret, M., Hirschberg, J. and Zamir, D. (2003). There is more to tomato fruit colour than candidate carotenoid genes. Plant Biotechnology Journal, 1, 195-207. https://doi.org/10.1046/j.1467-7652.2003.00018.x

Menezes, E. L.A. (2005). Inseticidas botânicos: Seus princípios ativos, modo de ação e uso agrícola [Documentos 205]. Seropédica: Embrapa Agrobiologia.

Rodríguez, A., Kava, V., Latorre-García, L., Silva Junior, G. J., Pereira, R. G., Glienke, C., Ferreira-Maba, L. S., Vicent, A., Shimada, T. and Peña, L. (2018). Engineering D-limonene synthase down-regulation in orange fruit induces resistance against the fungus Phyllosticta citricarpa through enhanced accumulation of monoterpene alcohols and activation of defence. Molecular Plant Pathology, 19, 20772093. https://doi.org/10.1111/mpp.12681

Rodríguez, A., Shimada, T., Cervera, M., Alquézar, B., Gadea, J., Gómez-Cadenas, A., De Ollas, C. J., Rodrigo, M. J., Zacarías, L. and Peña, L. (2014). Terpene down-regulation triggers defense responses in transgenic orange leading to resistance against fungal pathogens. Plant Physiology, 164, 321-339. https://doi.org/10.1104/pp.113.224279

Ronen, G., Carmel-Goren, L., Zamir, D. and Hirschberg, J. (2000). An alternative pathway to $\beta$-carotene formation in plant chromoplasts discovered by map-based cloning of Beta and old-gold color mutations in tomato. Proceedings of the National Academy of Sciences of United States of America, 97, 11102-11107. https://doi.org/10.1073/pnas.190177497

Singh, B. and Sharma, R. A. (2015). Plant terpenes: Defense responses, phylogenetic analysis, regulation and clinical applications. 3 Biotech, 5, 129-151. https://doi.org/10.1007/s13205-014-0220-2 
Sorensen, H. B. (1955). Methods of determining the optimum stage of maturity for picking green-wrap tomatoes. College Station: Texas Agricultural Experiment Station.

Story, E. N., Kopec, R. E., Schwartz, S. J. and Harris, G. K. (2010). An update on the health effects of tomato lycopene. Annual Review of Food Science and Technology, 1, 189-210. https://doi.org/10.1146/annurev.food.102308.124120

Tao, N., Jia, L., Zhou, H. (2014). Anti-fungal activity of Citrus reticulata Blanco essential oil against Penicillium italicum and Penicillium digitatum. Food Chemistry, 153, 265-271. https://doi.org/10.1016/j.foodchem.2013.12.070

Tieman, D., Bliss, P., McIntyre, L. M., Blandon-Ubeda, A., Bies, D., Odabasi, A. Z., Rodríguez, G. R., van der Knaap, E., Taylor, M. G., Goulet, C., Mageroy, M. H., Snyder, D. J., Colquhoun, T., Moskowitz, H., Clark, D. G., Sims, C., Bartoshuk, L. and Klee, H. J. (2012). The chemical interactions underlying tomato flavor preferences. Current Biology, 22, 1035-1039. https://doi.org/10.1016/j.cub.2012.04.016

Van Horn, L., Carson, J. A. S., Appel, L. J., Burke, L. E., Economos, C., Karmally, W., Lancaster, K., Lichtenstein, A. H., Johnson, R. K., Thomas, R. J., Vos, M., Wylie-Rosett, J. and Kris-Etherton, P. (2016). Recommended dietary pattern to achieve adherence to the American Heart Association/American College of Cardiology (AHA/ACC) guidelines: A scientific statement from the American Heart Association. Circulation, 134, e505-e529. https://doi.org/10.1161/CIR.0000000000000462

Vega-Vásquez, P., Mosier, N. S. and Irudayaraj, J. (2021). Nanovaccine for plants from organic waste: D-limonene-loaded chitosan nanocarriers protect plants against Botrytis cinerea. ACS Sustainable Chemical Engineering, 9, 9903-9914. https://doi.org/10.1021/ ACSSUSCHEMENG.1C02818

Vogel, J. T., Tieman, D. M., Sims, C. A., Odabasi, A. Z., Clark, D. G. and Klee, H. J. (2010). Carotenoid content impacts flavor acceptability in tomato (Solanum lycopersicum). Journal of the Science of Food and Agriculture, 90, 2233-2240. https://doi.org/10.1002/jsfa.4076

Yuan, H., Zhang, J., Nageswaran, D. and Li, L. (2015). Carotenoid metabolism and regulation in horticultural crops. Horticulture Research, 2, 15036. https://doi.org/10.1038/hortres.2015.36

Zahi, M. R., El Hattab, M., Liang, H. and Yuan, Q. (2017). Enhancing the antimicrobial activity of D-limonene nanoemulsion with the inclusion of $\varepsilon$-polylysine. Food Chemistry, 221, 18-23. https://doi.org/10.1016/j.foodchem.2016.10.037 